\title{
A IMPORTÂNCIA DA ADOÇÃO DE PRÁTICAS CONSENSUAIS PARA A GESTÃO DE CONFLITOS JURÍDICOS-FAMILIARES COMO POLÍTICA PÚBLICA DE CUMPRIMENTO DE OBJETIVO DO DESENVOLVIMENTO SUSTENTÁVEL
}

\section{Danielle Anne Pamplona}

Professora titular do Programa de Pós-Graduação em Direito da Pontifícia Universidade Católica do Paraná. Pós-Doutorado na Washington College of Law da American University (Washington, DC). Visiting Scholar no Max Planck Institut (Heidelberg, Alemanha). Doutora em Direito pela Universidade Federal de Santa Catarina. Mestre pela Pontificia Universidade Católica de São Paulo. Coordenadora da Clínica de Direitos Humanos da Pontifícia Universidade Católica do Paraná. Vice-diretora da Latin American Business and Human Rights Scholars Association.

\section{Dirce do Nascimento Pereira}

Doutoranda em Direito Socioambiental e Sustentabilidade pela Pontifícia Universidade Católica do Paraná. Mestre em Direito Econômico e Socioambiental pela Pontifícia Universidade Católica do Paraná. Professora assistente do Curso de Bacharelado em Direito da Universidade Estadual de Ponta Grossa - PR.

\begin{abstract}
Resumo: As transformações do conceito de família trouxeram consigo o reconhecimento tanto social como jurídico da pluralidade dos arranjos familiares. Diante da complexidade destes arranjos intensificaram-se as divergências e confrontos a respeito do tema, bem como a sua consequente judicialização, resultando na crescente necessidade de buscar mecanismos que objetivem a redução da carga processual e oportunizem às partes a tomada de decisão e a preservação dos vínculos parentais. Assim, esta pesquisa consiste em identificar a contribuição das práticas consensuais para a gestão de conflitos jurídico-familiares como política pública de cumprimento de objetivo do desenvolvimento sustentável. O método científico de abordagem é o lógico-dedutivo, partindo-se do estudo da transformação da família e a judicialização de seus conflitos para, após, avaliar a garantia do direito de acesso à justiça como direito humano por meio de políticas públicas de pacificação social. Finalizando o approach, discute-se a contribuição do Projeto de Extensão "Falando em Família" como uma das políticas públicas. Como resultado parcial, tem-se que a metodologia e os dados parciais do Projeto demonstram a efetividade da ação, que está em consonância com as orientações do Conselho Nacional de Justiça e com um dos Objetivos de Desenvolvimento Sustentável estabelecidos pela Organização das Nações Unidas.
\end{abstract}

Palavras-chave: Famílias neoconstituídas. Medidas consensuais. Pacificação de conflitos. Política pública. Desenvolvimento sustentável. 
Sumário: 1 Introdução - 2 A transformação da família como elemento indicativo da crescente judicialização dos conflitos familiares - $\mathbf{3} \mathrm{A}$ garantia do direito de acesso à justiça como direito humano por meio de políticas públicas voltadas à pacificação social - $\mathbf{4} \mathrm{A}$ contribuição do projeto de extensão falando em família como meio de implementação da política pública de incentivo às práticas consensuais no âmbito familiar - $\mathbf{5}$ Considerações finais - Referências

\section{Introdução}

Novos arranjos familiares foram construídos e com eles a iminência de conflitos passou a ser latente, considerando a complexidade gerada pela ampliação dos laços afetivos e parentais. Além disso, a fragilidade dos vínculos passou também a configurar como um fator determinante para que as partes em conflito afastem a possibilidade de diálogo e cedência e remetam ao Estado-juiz a responsabilidade de impor sua decisão, de acordo com a avaliação - por vezes objetiva - das provas contidas nos autos. Este comportamento das partes gera a proliferação de demandas judiciais que muitas vezes poderiam obter resultado a partir da atuação dos próprios demandantes.

0 atual cenário é alarmante e demonstra que a cultura da sentença continua arraigada, demonstrando ser uma regra quando se trata de solução de litígios. Isso facilmente se constata pela maneira como as pessoas se comportam diante de um iminente processo judicial, já que, via de regra, o impulso inicial é partir para o embate. Assim, as partes buscam no Poder Judiciário a solução como uma forma de obtenção de resultado vitorioso para um lado (e consequentemente a derrota do outro), parecendo ser a decisão verticalizada e hierarquizada a melhor escolha para solucionar seus conflitos.

Em 2015, a Organização das Nações Unidas estabeleceu seus objetivos globais, com uma pauta a ser desenvolvida até 2030 , em que estão listados os dezessete Objetivos de Desenvolvimento Sustentável (ODS). O ODS número 16 foi denominado Paz, Justiça e Instituições Eficazes e é expresso nos seguintes termos: "Promover sociedades pacíficas e inclusivas para o desenvolvimento sustentável, proporcionar o acesso à justiça para todos e construir instituições eficazes, responsáveis e inclusivas em todos os níveis". ${ }^{1}$

Duas das metas estabelecidas para o referido objetivo têm relação íntima com este trabalho. Em primeiro lugar, a que estabelece que deve ser garantida

1 ORGANIZAÇÃO DAS NAÇÕES UNIDAS NO BRASIL (ONU). Agenda 2030. Disponível em: https:// nacoesunidas.org/pos2015/ods16/. Acesso em: 25 maio 2018. 
a igualdade de acesso à justiça para todos. Em segundo, a que determina que deve ser garantida a tomada de decisões inclusivas e participativas. Partimos deste Objetivo de Desenvolvimento Sustentável para defender a utilização de uma forma diferenciada de resolução de conflitos que envolvam famílias com base na experiência realizada na Universidade Estadual de Ponta Grossa, Estado do Paraná.

Desta forma, a partir do método científico de abordagem lógico-dedutivo, pretende-se iniciar pelo estudo da transformação da família e a judicialização de seus conflitos para, após, avaliar a garantia do direito de acesso à justiça como direito humano fundamental por meio de políticas públicas de pacificação social. Ao final discute-se a contribuição do Projeto de Extensão "Falando em Família" como possibilidade de implementação de política pública nestes termos. Como resultado parcial, tem-se que a metodologia e os dados parciais do Projeto demonstram a efetividade da ação, que está em consonância com as orientações do Conselho Nacional de Justiça e com um dos Objetivos de Desenvolvimento Sustentável (estabelecidos pela Organização das Nações Unidas).

Propõe-se como problema de pesquisa identificar a contribuição das práticas consensuais para a gestão de conflitos jurídico-familiares como política pública de cumprimento de objetivo do desenvolvimento sustentável mencionado.

A hipótese confirmadora do problema que ora se propõe fundamenta-se na afirmação de que há contribuição, em especial das ações do Projeto de Extensão "Falando em Família", considerando a multiplicidade de atores envolvidos, a possibilidade de continuidade das ações, o empenho para o efetivo acesso à justiça, a promoção de sociedades mais pacíficas e inclusivas, a partir do direcionamento de instrumentos para concretização destas ações com a formação de um ambiente autônomo de decisão por parte dos maiores interessados na gestão do conflito.

Parte-se da ideia de que a solução de conflitos é geralmente estabelecida com base em um paradigma de paternalismo estatal. No entanto, é preciso reconhecer que ele está aos poucos sendo afastado para viabilizar às partes a tomada de decisão. Isto se deve às efetivas tentativas de mudanças deste quadro, seja pela entrada em vigor do Código de Processo Civil, que trouxe a proposta da busca do direito conciliatório, seja por parte do Conselho Nacional de Justiça, por intermédio de programas e mecanismos que incentivam a cultura da pacificação e da conciliação (Resolução no 125/2010). Além disto, as instituições de ensino superior estão gradativamente incluindo disciplinas e projetos que incentivam 0 caráter consensual nos conflitos das mais diversas espécies em suas grades curriculares, por exemplo, aqueles que envolvem o Direito das Famílias, o Direito Empresarial e a Administração Pública. 
Há necessidade da reconstrução do paradigma de Justiça e consequentemente da restauração da força decisória autônoma das partes, restabelecendo o poder que ficou diluído durante o conflito, afastando a intervenção de terceiro e tornando possível o diálogo e o poder decisório isento e independente das partes envolvidas.

Passa-se a dar destaque ao fato de a adoção de mecanismos alternativos à via judicial ser extremamente importante não somente para reduzir a carga processual do Poder Judiciário, mas principalmente no Direito das Famílias, para oportunizar a tomada de decisão, além da consequente preservação dos vínculos entre as partes e, de modo especial, dos elos parentais.

Para que seja possivel ampliar as ações que já vêm sendo adotadas por parte do Poder Judiciário faz-se necessário recorrer ao Estado para apresentar outros mecanismos aptos a disseminar a pacificação social no âmbito familiar e buscar a institucionalização, por meio de política pública, de práticas consensuais que apresentaram resultado positivos.

Deste modo, busca-se demonstrar que as relações familiares representam percentual significativo de demandas judiciais, mas que há possibilidade de gestão deste atual e alarmante contexto. E isto é possível a partir da implementação de ações que contribuam não somente para o aumento da formalização de acordos na via judicial, mas que também tenham condições de minimizar o conflito familiar instalado e principalmente preservar os laços paterno e materno-filiais.

\section{A transformação da família como elemento indicativo da crescente judicialização dos conflitos familiares}

Não é possivel fechar os olhos para a transformação pela qual perpassa a família, seja no que se refere a construção dos novos arranjos familiares, a função exercida pela família, bem como a estruturação da legislação em uma tentativa de abarcar os reflexos advindos desta nova realidade, que geram consequências tanto em relação ao vínculo conjugal como ao vínculo parental.

Vários papéis foram e continuam sendo desempenhados pela família. Porém, ora voltados exclusivamente para a manutenção da família reunida, a partir de um determinado alicerce - religioso, econômico ou procracional -, ora direcionado à dignificação de seus membros com respeito à liberdade de cada indivíduo e de sua relação com a sociedade, mas ainda assim preservando a família, não necessariamente entendida como a manutenção de seus membros em coabitação, mas sim pela preservação dos vínculos que se mantêm presentes mesmo que a convivência constante entre eles não seja uma realidade. 
Portanto, a função da família, no aspecto de desempenho de um dever ou o cumprimento de uma finalidade, ${ }^{2}$ foi sendo transformada no decorrer dos tempos, ressaltando a função prevalente em cada momento histórico, de acordo com os contextos social, político, econômico e religioso vivenciados.

Da análise da função religiosa familiar é possível afirmar que ela representava o fundamento da união entre os membros da família, possibilitando, por exemplo, o afastamento da filha casada e do filho que renunciasse ao culto sagrado ou que se tornasse emancipado, mesmo diante da existência de consanguinidade. Possibilitava ainda a substituição do marido estéril por um irmão ou parente do marido, permitindo que a mulher se entregasse a esse homem, porém considerando a criança nascida desta relação filha do marido estéril.

O que une os membros da família é algo mais potente que o nascimento, o sentimento, a força física: é a religião do lar e dos antepassados. Ela faz que a família forme uma unidade nesta vida e na outra. A família antiga é uma associação religiosa, mais ainda do que uma associação natural. $^{3}$

A função religiosa da família era tão contundente que, para sustentar a reverência aos deuses, a manutenção do fogo sagrado e da própria família, a adoção passou a ser reconhecida pelo Direito romano àqueles que eventualmente não pudessem ter filhos, ${ }^{4}$ mas por outro lado as relações extramatrimoniais e, consequentemente o filho bastardo, eram totalmente preteridos. A existência do vínculo biológico em relação ao filho bastardo não conferia a este nenhum direito. ${ }^{5}$ Além da predominância da religião, não somente como fundamento para caracterização da família romana, mas como finalidade, outro fator evidenciado era o domínio da autoridade do pater que cumulava as atribuições de chefe político, chefe religioso, juiz e ainda exercia plenos poderes em relação aos filhos e à mulher, podendo decidir, inclusive, sobre o exercício do direito de viver e morrer. Os filhos podiam sofrer violência corporal e ainda ser objeto de comercialização e a mulher não possuía capacidade jurídica, não sendo assegurado nenhum direito a ela, pois era atingida pela chamada capitis diminutio perpétua. ${ }^{6}$ Mesmo diante da

2 GAMA, Guilherme Calmon Nogueira da; ANDRIOTTI, Caroline Dias. Breves notas históricas da função social no Direito Civil. In: GAMA, Guilherme Calmon Nogueira da (Coord.). Função social no direito civil. 2. ed. São Paulo: Atlas, 2008.

3 FUSTEL DE COULANGES, Numa Denis. A cidade antiga. 4. ed. Trad. Fernando Aguiar. São Paulo: Martins Fontes, 1998, p. 53.

4 PEREIRA, Caio Mario da Silva. Reconhecimento de paternidade e seus efeitos. 5. ed. Rio de Janeiro: Forense, 1998.

5 Ibidem.

6 PEREIRA, Caio Mario da Silva. Instituições de direito civil. Rio de janeiro: Forense, 2011. 
impossibilidade de se atribuir momentos estanques para a transposição das funções da família ao longo dos tempos, bem como afastar totalmente uma determinada função em substituição a outra, é possível afirmar que a função religiosa foi aos poucos abrindo espaço para a função política, em que a família buscava junto ao Estado a realização de interesses eminentemente privados, especialmente a consolidação dos clãs. ${ }^{7} A$ função econômica da família também teve seu âmbito de sustentação e estava diretamente relacionada à função procracional, já que a manutenção da família dependia do seu número de integrantes. No entanto, com a transferência da atribuição econômica à previdência social, a família, na qualidade de unidade produtiva, passou por um período de decadência, reduzindo gradativamente sua função procracional. ${ }^{8}$

As características da estrutura organizacional familiar e a consequente função que exercia em relação aos membros de uma família permaneceram edificadas inclusive na legislação brasileira em vigor no início do século XX. Esta menção pode ser verificada a partir da análise do Código Civil de 1916, que identificava a família patriarcal, hierarquizada e ainda sob forte influência da religião, admitindo o casamento como única forma de reconhecimento da família sob o manto da religião e da lei. Os filhos concebidos fora do casamento eram considerados ilegítimos e, portanto, recebiam tratamento diferenciado. A mulher continuava submissa ao poder marital e os filhos subservientes ao pátrio poder.

A transformação da sociedade, principalmente após os períodos de industrialização e de urbanização, influenciou significativamente a concepção da estrutura familiar, sendo necessária uma readequação de seus parâmetros diante do novo cenário.

No âmbito nacional mudanças importantes marcaram essa readequação. A mulher casada foi emancipada, a partir da entrada em vigor do Estatuto da Mulher Casada (Lei no 4.121/1962). ${ }^{9}$ No entanto, o marido continuava sendo o chefe da sociedade conjugal e a mulher podia somente colaborar com ele, com o objetivo de preservar os interesses comuns do casal e dos filhos, de acordo com a redação dada pela mencionada lei ao artigo 233 do Código Civil. ${ }^{10}$

7 GILISSEN, John. Introdução histórica ao direito. 2. ed. Trad. A. M. Hespanha e L. M. Macaísta Maíheiros. Lisboa: Calouste Gulbenkian, 1995.

8 LÔBO, Paulo. Direito civil: família. 4. ed. São Paulo: Saraiva, 2011.

9 BRASIL. Lei 4.121 de 27 de agosto de 1962. Dispõe sobre a situação jurídica da mulher casada. Disponivel em: http://www.planalto.gov.br/ccivil_03/leis/1950-1969/L4121.htm. Acesso em: 18 abr. 2018.

10 BRASIL. Lei 4.121 de 27 de agosto de 1962. Dispõe sobre a situação jurídica da mulher casada. Disponível em: http://www.planalto.gov.br/ccivil_03/leis/1950-1969/L4121.htm. Acesso em: 18 abr. 2018. 
A indissolubilidade do vínculo conjugal deixou de existir com a entrada em vigor da Lei do Divórcio (Lei no 6.515/1977). ${ }^{11}$ Apesar de esta medida ter representado um avanço em relação a organização familiar, pois contribuiu para o reconhecimento da igualdade da mulher, ainda havia resquícios da busca pela manutenção do matrimônio, obstaculizando o pedido de divórcio ao estabelecer condições e prazos para a sua viabilidade. A intervenção estatal ainda era uma constante realidade no cotidiano da família brasileira.

Assim como a mulher ganhou espaço e reconhecimento - embora de forma sutil e gradativa -, a criança também passou a ser protegida e seus direitos foram assegurados pela Declaração de Genebra sobre os Direitos da Criança, de 1924; pela Declaração Universal dos Direitos da Criança, de 1959; e pela Convenção sobre os Direitos da Criança, de 1990, promulgada pelo Decreto oㅡ 99.710/1990.12 A partir da Constituição de 1988 e suas posteriores alterações, a proteção foi estendida também ao adolescente, ao jovem e ao idoso, reafirmada com a entrada em vigor do Estatuto da Criança e do Adolescente (Lei no 8.069/1990), ${ }^{13}$ além do Estatuto do Idoso (Lei oㅜ 10.741/2003) ${ }^{14}$ e do Estatuto da Juventude (Lei no 12.852/2013)..$^{15}$

No campo normativo, com a democratização das relações familiares, a partir da entrada em vigor da Constituição de 1988, a família matrimonializada, hierarquizada e patriarcal foi substituída pela coordenação e comunhão de interesses de vida, ${ }^{16}$ pela igualdade entre homem e mulher, pela possibilidade irrestrita da dissolubilidade do vínculo conjugal, pelo reconhecimento da família monoparental, da relação homoafetiva e da união estável como entidades familiares. Com inspiração nos princípios da dignidade da pessoa humana, da igualdade entre os filhos, da solidariedade familiar, bem como da afetividade, a

11 BRASIL. Lei no 6.515 de 26 de dezembro de 1977. Regula os casos de dissolução da sociedade conjugal e do casamento, seus efeitos e respectivos processos, e dá outras providências. Disponível em: http:// www.planalto.gov.br/ccivil_03/leis/L6515.htm. Acesso em: 18 abr. 2018.

12 BRASIL. Decreto no 99.710, de 21 de novembro de 1990. Promulga a Convenção sobre os Direitos da Criança. Disponível em: http://www.planalto.gov.br/ccivil_03/decreto/1990-1994/d99710.htm. Acesso em: 18 abr. 2018.

13 BRASIL. Lei no 8.069, de 13 de julho de 1990. Dispõe sobre o Estatuto da Criança e do Adolescente e dá outras providências. Disponível em: http://www.planalto.gov.br/ccivil_03/leis/L8069.htm. Acesso em: 18 abr. 2018.

14 BRASIL. Lei no 10.741, de 1ํ de outubro de 2003. Dispõe sobre o Estatuto do Idoso e dá outras providências. Disponível em: http://www.planalto.gov.br/ccivil_03/leis/2003/L10.741.htm. Acesso em: 18 abr. 2018.

15 BRASIL. Lei no 12.852, de 5 de agosto de 2013. Institui o Estatuto da Juventude e dispõe sobre os direitos dos jovens, os princípios e diretrizes das políticas públicas de juventude e o Sistema Nacional de Juventude SINAJUVE. Disponível em: http://www.planalto.gov.br/ccivil_03/_ato2011-2014/2013/lei/l12852.htm. Acesso em: 18 abr. 2018.

16 LÔBO, Paulo. Direito civil: família. 4. ed. São Paulo: Saraiva, 2011. 
família passou a ser compreendida como um fenômeno cultural. ${ }^{17}$ Neste sentido, a função da família também sofreu transformação com o "deslocamento da função econômica-política-religiosa-procracional" para "converter-se em espaço de realização da afetividade humana" ${ }^{18}$ e a instituição familiar passou a ser considerada "um núcleo afetivo, voltado para a promoção da personalidade e da dignidade de seus membros. A família passou a existir em função de seus componentes, e não o contrário" ${ }^{19}$ Portanto, é a função afetiva que passa a preponderar no âmbito familiar. Mais que a nobreza sentimental ou os mais repudiados sentimentos, ${ }^{20}$ a afetividade passa a solidificar os vínculos a partir da sua transcendência aos fatos psicossociais, uma vez que se converte em fato jurídico, ${ }^{21}$ inclusive com reflexos sociais, jurídicos e normativos. Torna-se "dever imposto aos pais em relação aos filhos e destes em relação àqueles, ainda que haja desamor ou desafeição entre eles". ${ }^{22}$ Ao afeto passa a ser atribuído valor jurídico. ${ }^{23} \mathrm{Em}$ que pese não haver previsão constitucional expressa da afetividade como princípio na seara familiar, ele está implicitamente inscrito na base axiológica, a partir da interpretação principiológica que fundamenta o sistema constitucional brasileiro, assim como pode ser interpretado a partir de determinados dispositivos legais, a exemplo do artigo 1.593 do Código Civil, ${ }^{24}$ que amplia a vinculação paterno ou materno-filial a outras formas que vão além da origem consanguínea.

A partir deste contexto, uma série de consequências na relação paterno e materno-filial advém, como o direito à guarda unilateral ou compartilhada, o exercício do direito de visitas, a prestação alimentar, o dever de cuidado e proteção, a impossibilidade de qualquer ato que caracterize o abandono afetivo ou a alienação parental.

Gradativamente, a função afetiva é abarcada pela função social da família, considerando que o afeto representa uma das condições propícias à criação de um ambiente harmônico e favorável à convivência familiar. Em tempos remotos, os membros agiam em razão da família, era o que ocorria, por exemplo, quando

17 PEREIRA, Dirce do Nascimento Pereira. O reconhecimento da paternidade simultânea e seus reflexos jurídicos na seara sucessória. In: CONSALTER, Zilda Mara; PEREIRA, Dirce do Nascimento Pereira (Org.). Questões controversas do direito das famílias na contemporaneidade. Belo Horizonte: Arraes, 2015.

18 LÔBO. Op. cit., p. 22.

19 TEIXEIRA, Ana Carolina Brochado. Novas entidades familiares. In: Revista Trimestral de Direito Civil. Rio de Janeiro, v. 16, out./dez., 2003. p. 3.

20 ROCHA, Marco Túlio de Carvalho. O conceito de família e suas implicações jurídicas: teoria sociojurídica do direito de família. Rio de Janeiro: Elsevier, 2009.

21 LÔBO. Ibid.

22 Ibidem, p. 71.

23 DIAS, Maria Berenice. Manual de direito das famílias. 8. ed. rev. e atual. São Paulo: Revista dos Tribunais, 2011.

24 BRASIL. Lei o 10.406, de 10 de janeiro de 2002. Institui o Código Civil. Disponível em: http://www. planalto.gov.br/ccivil_03/leis/2002/L10406.htm. Acesso em: 18 abr. 2018. 
os cônjuges não tinham possibilidade real de manutenção de uma convivência saudável, mas ainda assim permaneciam juntos a fim de consolidarem a indissolubilidade matrimonial e não violarem a máxima "até que a morte nos separe". Isto muitas vezes gerava - e ainda gera em determinadas situações - um desgaste emocional significativo e consequentemente afastava o pleno exercício da dignidade da pessoa humana, tanto sob o aspecto da proteção e liberdade do indivíduo como também sob o prisma da sua integração na sociedade.

Atualmente, para que a família atenda a sua função social faz-se necessário que o grupo familiar atue em razão dos seus integrantes - e não ao contrário proporcionado "um lugar privilegiado para a boa vivência e dignificação de seus membros", ${ }^{25}$ configurando um refúgio contra os riscos e temores presentes na vida em sociedade, mas também fazendo com que o seio familiar se torne um ambiente de aprendizagem, a fim de não somente representar proteção, mas acima de tudo suporte para o efetivo exercício da cidadania, tanto na comunidade em que vivem como na sociedade de maneira geral. A subserviência e a aquiescência contumaz devem ser substituídas pelo reconhecimento da importância do papel ativo de cada indivíduo na família e na sociedade.

Portanto, é incontestável a transformação sob a perspectiva dos vínculos familiares. Os integrantes de uma organização familiar que estiveram há muito tempo sob o véu da invisibilidade passaram a poder exercer direitos e exigir respeito à liberdade de agir. A pluralidade das configurações familiares também começou a ganhar espaço e a função da família, até então padronizada e direcionada à manutenção da conjugalidade, foi flexibilizada pelos vínculos, ampliada pelo suporte emocional e permeada pela preservação da dignidade dos seus membros.

$\mathrm{Na}$ medida em que se identifica a ampliação do cenário familiar, bem como a intensidade dos laços afetivos, vislumbra-se também maior fragilidade destas relações. A “proximidade virtual" ${ }^{26}$ contribuiu para a volubilidade dos comportamentos humanos e consequentemente para a inequívoca complexidade da manutenção harmoniosa dos novos arranjos familiares. Segundo Bauman:

O advento da proximidade virtual torna as conexões humanas simultaneamente mais frequentes e mais banais, mais intensas e mais breves. As conexões tendem a ser demasiadamente breves e banais para poderem condensar-se em laços. [...] Os contatos exigem menos tempo e esforço para serem estabelecidos, e também para

25 GAMA, Guilherme Calmon Nogueira da; GUERRA, Leandro dos Santos. Função social da família. In: GAMA, Guilherme Calmon Nogueira da (Coord.). Função social no direito civil. 2. ed. São Paulo: Atlas, 2008, p. 136.

26 BAUMAN, Zygmunt. Amor líquido: sobre a fragilidade dos laços humanos. Trad. Carlos Alberto Medeiros. Rio de Janeiro: Zahar, 2004, p. 82. 
serem rompidos. A distância não é obstáculo para se entrar em contato - mas entrar em contato não é obstáculo para se permanecer à parte. Os espasmos da proximidade virtual terminam, idealmente, sem sobras nem sedimentos permanentes. Ela pode ser encerrada, real e metaforicamente, sem nada mais que o apertar de um botão. ${ }^{27}$

A ausência de solidez nas relações familiares propicia um ambiente de divergências e confrontos em que as partes envolvidas se sentem impossibilitadas de buscar outra alternativa senão a judicialização dos conflitos. Este caminho parece ser a única forma viável para solucionar a situação conflituosa em que as partes se inserem. De fato, a cada dia as relações familiares estão mais embrenhadas em questões jurídicas do que em questões naturais. ${ }^{28}$ Ainda de acordo com Bauman:

A história do direito da família ilustra a lenta penetração da justiça para controlar as relações familiares e a aceleração desta evolução muito sensivel nestes últimos anos. As relações entre pais e filhos judicializaram-se progressivamente compreendendo-se em cada dia mais em termos jurídicos do que naturais. ${ }^{29}$

A judicialização das demandas sobrecarrega o Poder Judiciário de ações que nem sempre deveriam ser decididas pela autoridade estatal, uma vez que determinados conflitos jurídicos poderiam ser resolvidos pelas próprias partes, sem que houvesse a necessidade da intervenção do Estado-juiz. Outra consequência da decisão verticalizada é a identificação pelas partes, a posteriori, de que a sentença judicial cumpriu com o seu papel no sentido de extinguir o processo, porém não necessariamente teve o condão de afastar efetivamente o dissenso em relação à questão objeto da demanda. "É o que ocorre no julgamento dos processos pelo sistema tradicional, uma vez que a preocupação do Estado vai 'até a sentença'". 30

De acordo com o Conselho Nacional de Justiça, ${ }^{31}$ em 2009 o número de processos em trâmite na Justiça Estadual brasileira aproximou-se de 49 milhões,

\footnotetext{
BAUMAN. Ibidem.

28 GARAPON, Antoine. O guardador de promessas. Justiça e democracia. Trad. Francisco Aragão. Lisboa: Instituto Piaget, 1996.

29 Idem, p. 150.

30 MERLO, Sandra Regina; MARGRAF, Alencar Frederico. Justiça restaurativa: possibilidade ou utopia? In: HELLMANN, Renê Francisco; MARGRAF, Alencar Frederico (Org.). Os efeitos do constitucionalismo contemporâneo no direito: uma visão interdisciplinar. Telêmaco Borba: FATEB, 2014, p. 310.

31 CONSELHO NACIONAL DE JUSTIÇA (CNJ). Justiça em números: publicado em 2016 referente ano-base 2015. Disponivel em: http://www.cnj.jus.br/files/conteudo/arquivo/2016/10/ b8f46be3dbbff344931a933579915488.pdf. Acesso em: 15 maio 2018.
} 
aumentando em 10 milhões no decurso de seis anos, ou seja, em 2015 o número de processos pendentes no âmbito da Justiça Estadual alcançou 59 milhões. No período compreendido entre 2014 e 2016, as questões relacionadas ao Direito das Famílias estiveram entre os 20 assuntos mais demandados na Justiça Estadual, em primeiro grau de jurisdição. ${ }^{32-33-34}$

Os números apresentados demonstram o reflexo da transformação e da complexidade das relações familiares, bem como a confiança depositada pelas partes na atuação do Estado-juiz como a única forma encontrada para a solução dos conflitos em que estão inseridas. No entanto, a via judicial não pode ser considerada uma via exclusiva para a solução de demandas, pois, em se tratando de conflito jurídico-familiar, há sentimentos e interesses envolvidos que vão além da seara jurídica, os quais podem ser inclusive acentuados a partir da prolação de uma sentença judicial. Nesta situação, retroceder pode ser a melhor conduta a ser adotada, já que "a atividade não estatal de solução de controvérsias surgiu antes do Estado"35.

Para Rodolfo de Camargo Mancuso:

[...] desde as priscas eras romanas, a resolução dos conflitos se fazia, ou entre os próprios contendores, pelas várias formas de autotutela, ou mediante a intercessão de um árbitro privado, para tal convocado pelas partes; só na terceira e última fase do processo romano - a extraordinária cognitio - é que o magistrado se encontrava revestido do poder estatal. ${ }^{36}$

O direito fundamental de acesso à justiça, previsto no artigo 5으, XXXV, da Constituição de 1988, deve ser analisado como uma cláusula de reserva a fim de afastar a via judicial como primeira e única opção a ser adotada pelas partes por ocasião de um conflito jurídico-familiar. Isto não significa atribuir menor importância à via judicial, mas sim viabilizar que a adoção de práticas consensuais possa

32 CONSELHO NACIONAL DE JUSTIÇA (CNJ). Justiça em números: publicado em 2015 referente ano-base 2014. Disponível em: http://www.cnj.jus.br/programas-e-acoes/pj-justica-em-numeros. Acesso em: 20 maio 2018.

33 CONSELHO NACIONAL DE JUSTIÇA (CNJ). Justiça em números: publicado em 2016 referente ano-base 2015. Disponível em: http://www.cnj.jus.br/files/conteudo/arquivo/2016/10/ b8f46be3dbbff344931a933579915488.pdf. Acesso em: 15 maio 2018.

34 CONSELHO NACIONAL DE JUSTIÇA (CNJ). Justiça em números: publicado em 2017 referente ano-base 2016. Disponível em: http://www.cnj.jus.br/files/conteudo/arquivo/2017/12/ b60a659e5d5cb79337945c1dd137496c.pdf. Acesso em: 15 maio 2018.

35 BENETI, Sidnei Agostinho. Resolução alternativa de conflitos (ADR) e constitucionalidade. In: Revista do Instituto dos Advogados de São Paulo (IASP). n. 9, jan.jul. 2002, p. 121.

36 MANCUSO, Rodolfo de Camargo. Acesso à justiça: condicionantes legítimas e ilegítimas. 2. ed. rev., atual. e ampl. São Paulo: Revista dos Tribunais, 2015, p. 165-166. 
coexistir com a intervenção judicial, oportunizando a convivência com iniciativas inovadoras de solução de conflitos denominada por Nalini ${ }^{37}$ "justiça partilhada".

Garapon $^{38}$ coaduna com este pensamento quando, ao tratar das práticas consensuais como a mediação civil ou penal e arbitragem comercial, afirma que "trata-se de lugares aparentemente exteriores à justiça, e, no entanto, ela não está ausente, longe disso. Eles têm em comum, efetivamente, o pedir emprestado à justiça o seu método".

Esta mudança de concepção pode ser vislumbrada não somente pela regulamentação de práticas consensuais pelo ordenamento jurídico brasileiro, mas também pelas ações adotadas pelo Conselho Nacional de Justiça no sentido de implementar políticas públicas que possam minimizar a sobrecarga do Poder Judiciário e delimitar os conflitos familiares que requerem efetiva solução.

\section{A garantia do direito de acesso à justiça como direito humano por meio de políticas públicas voltadas à pacificação social}

Considerando a impossibilidade da utilização da autotutela em um Estado Democrático de Direito, surge a responsabilidade do Estado de solucionar os conflitos sociais, a fim de substituir a vontade das partes. 0 inciso XXXV do artigo 5ㅇ da Constituição Federal de 1988 prevê que: "a lei não excluirá da apreciação do Poder Judiciário lesão ou ameaça a direito”. Segundo Watanabe, ${ }^{39}$ o mencionado dispositivo deve ser interpretado “não apenas como garantia de acesso ao Judiciário, mas como garantia de acesso à ordem jurídica justa, de forma efetiva, tempestiva e adequada."O artigo 8 da Declaração Universal de Direitos Humanos estabelece que "toda a pessoa tem direito a recurso efectivo para as jurisdições nacionais competentes contra os actos que violem os direitos fundamentais reconhecidos pela Constituição ou pela lei", garantindo a todos a proteção jurisdicional efetiva contra os atos que violem os direitos fundamentais reconhecidos normativamente. Em conformidade com este reconhecimento internacional, o artigo 25 da Convenção Americana de Direitos Humanos - Pacto de San José da Costa Rica - também reforça a previsão do direito à tutela jurisdicional célere e efetiva.

NALINI, José Renato. A rebelião da toga. 3. ed. rev., atual. e ampl. São Paulo: Revista dos Tribunais, 2015, p. 213.

38 GARAPON. Op. cit., p. 242.

39 WATANABE, Kazuo. Política pública do Poder Judiciário nacional para tratamento adequado dos conflitos de interesses. In: Revista de Processo, n. 195, maio/2011, p. 384-385. 
Ainda se faz importante trazer à lume as preocupações apresentadas por Amartya $\mathrm{Sen}^{40}$ no que se refere a alguns temas passíveis de críticas acerca da real identificação dos direitos humanos e, neste sentido, constatar a ligação entre o direito de acesso à justiça como direito humano fundamental.

A primeira delas é denominada "crítica da legitimidade", ${ }^{41}$ em que a discussão está em reconhecer os direitos humanos como consequência do sistema legal e questionar esta possibilidade advinda de pretensões morais pré-legais, as quais não poderiam proporcionar a uma pessoa um direito juridicamente exigivel. A segunda preocupação está relacionada à necessidade de que os "direitos só podem ser formulados sensatamente em combinação com deveres correlatos", ou seja, "o direito de uma pessoa a alguma coisa deve corresponder ao dever de outro agente de dar à primeira pessoa esta coisa", o que é denominado "crítica da coerência". ${ }^{42} \mathrm{E}$ a terceira preocupação se refere ao questionamento quanto à universalidade dos direitos humanos, a qual é denominada como "crítica cultural". ${ }^{43}$

Neste sentido, o direito de acesso à justiça suplanta as referidas críticas, uma vez que se trata de direito formalmente previsto na Constituição brasileira e, portanto, juridicamente exigível. Além disso, é possível identificar o dever do Estado, por meio do Poder Judiciário, de garantir a fruição deste direito, principalmente viabilizando a tutela jurisdicional célere e efetiva, podendo ser responsabilizado pelos prejuízos gerados pela omissão e desrespeito a este direito fundamental de real acesso à justiça. Por outro lado, a crítica à universalidade dos direitos humanos também resta afastada, pois o direito de acesso à justiça é reconhecido pela Declaração de Direitos Humanos, bem como pela Convenção Americana de Direitos Humanos (Pacto de São José da Costa Rica). Fábio Konder Comparato nos acrescenta afirmando que:

[...] direitos fundamentais são os direitos humanos reconhecidos como tais pelas autoridades às quais se atribui o poder político de editar normas, tanto no interior dos Estados quanto no plano internacional; são os direitos humanos positivados nas Constituições, nas leis, nos tratados internacionais. ${ }^{44}$

\footnotetext{
40 SEN, Amartya Kumar. Desenvolvimento como liberdade. Trad. Laura Teixeira Motta. São Paulo: Companhia das Letras, 2000.

41 Idem, p. 263.

42 Ibidem, p. 264.

43 Ibidem, p. 265.

44 COMPARATO, Fábio Konder. A afirmação histórica dos direitos humanos. 5. ed. rev. e atual. São Paulo: Saraiva, 2007, p. 59.
} 
Nessa linha, Boaventura de Souza Santos e Marilena Chauí afirmam que "a grande maioria da população mundial não é sujeito de direitos humanos. É objeto de discursos de direitos humanos". ${ }^{45}$ Assim, é importante contribuir para que esta constatação possa, ao menos, ser minimizada no que se refere ao exercício do direito de acesso à justiça no âmbito nacional. Não é possível admitir o direito de acesso à justiça sendo entendido na prática como a possibilidade do ajuizamento de uma ação e a consequente sentença judicial, independentemente de seus termos, lapso temporal e eficácia. Alvin Toffler ensina que:

O mundo que está emergindo rapidamente do choque de novos valores e tecnologias, novas relações geopolíticas, novos estilos de vida e novos modos de comunicação, exige ideias e analogias novas, novas classificações e novos conceitos. Não podemos enfiar o mundo embrionário de manhã em cubículos convencionais. Nem as atitudes nem os modos são apropriados. ${ }^{46}$

Portanto, o acesso à justiça passou a representar um direito humano fundamental previsto constitucionalmente e reconhecido internacionalmente, passando não mais a caracterizar o direito de buscar a prestação jurisdicional, mas sim que a tutela estatal seja efetiva e propicie a gestão do conflito, atendendo ao princípio da razoável duração do processo.

De acordo com o quanto já estabelecido, um dos Objetivos de Desenvolvimento Sustentável é a promoção de sociedades que viabilizem o acesso à justiça. Perceba-se que esta dicção não exige o acesso ao Judiciário, em reconhecimento de que, por vezes, a justiça pode vir por outros caminhos.

No Brasil, visando a "transformar espaços decisórios em cenários menos burocráticos e mais democráticos", ${ }^{47}$ as medidas alternativas de gestão de conflitos são louvadas pela Constituição, valorizadas pelo novo Código de Processo Civil e, hoje, contam com legislação específica sobre o tema.

Em 1988, os parlamentares responsáveis pela elaboração da Constituição brasileira deram os primeiros passos para a criação de um ambiente favorável a iniciativas legislativas específicas com vistas à implementação de instrumentos mais pacificadores de conflitos ao estabelecerem, no preâmbulo da Carta, que o Estado Brasileiro está fundamentado e comprometido "na ordem interna e internacional com a solução pacífica das controvérsias".

45 SANTOS, Boaventura de Sousa; CHAUÍ, Marilena. Direitos humanos, democracia e desenvolvimento. São Paulo: Cortez, 2013, p. 42.

46 TOFFLER, Alvin. A terceira onda. 32. ed. Trad. João Távora. Rio de Janeiro: Record, 2014, p. 16.

47 SALM, João; LEAL, Jackson da Silva. A justiça restaurativa: multidimensionalidade humana e seu convidado de honra. In: Sequência, n. 64, p. 195-226, jul. 2012, p. 196. 
A nova redação do Código de Processo Civil vem na mesma toada ao incentivar a solução consensual de conflitos entre as partes, pois dispõe que nas ações serão empreendidos todos os esforços para a solução consensual da controvérsia, devendo o juiz contar com o auxílio de profissionais de outras áreas de conhecimento para a mediação e conciliação. Em sua parte geral, especificamente nos $\S \S 2^{\circ}$ e $3^{\circ}$ de seu artigo $2^{\circ}$, estabelece que:

[...] §2ㅇ O Estado promoverá, sempre que possível, a solução consensual dos conflitos. §3ำ A conciliação, a mediação e outros métodos de solução consensual de conflitos deverão ser estimulados por juízes, advogados, defensores públicos e membros do Ministério Público, inclusive no curso do processo judicial. ${ }^{48}$

Em 2015, foi publicada a Lei № 13.140, ${ }^{49}$ que dispõe sobre a mediação como meio de solução de controvérsias entre particulares e sobre a autocomposição de conflitos no âmbito da Administração Pública.

Diante disto, as medidas alternativas de gestão de conflitos passaram a representar uma mudança na perspectiva de compreensão do então denominado direito à proteção judiciária, presente nos Estados liberais burgueses dos séculos XVIII e XIV, quando reinava uma filosofia eminentemente individualista, na medida em que representava basicamente o direito formal do cidadão de petição ao Poder Judiciário. ${ }^{50}$

Utilizar mecanismos aptos a efetivar a gestão de conflitos contemporâneos na seara familiar representa contribuir para afastar a ineficácia da prestação jurisdicional tardia, a qual fragiliza e transforma em utopia o direito pleiteado pelas partes, por mais meritória que represente o conteúdo da decisão judicial.

Considerando, portanto, que o direito de acesso à justiça é um direito humano fundamental e que somente se materializa a partir da real prestação jurisdicional, é possível constatar que os meios alternativos de solução de conflitos representam um mecanismo que propicia a efetivação da formalidade normativa. Segundo Carlos Alberto Menezes Direito:

48 BRASIL. Lei no 13.105, de 16 de março de 2015. Institui o Código de Processo Civil. Disponível em: http://www.planalto.gov.br/ccivil_03/ato2015-2018/2015/lei/l13105.htm. Acesso em: 20 abr. 2018.

49 BRASIL. Lei no 13.140 de 26 de junho de 2015. Dispõe sobre a mediação entre particulares como meio de solução de controvérsias e sobre a autocomposição de conflitos no âmbito da administração pública. Disponível em: http://www.planalto.gov.br/ccivil_03/_ato2015-2018/2015/lei/l13140.htm. Acesso em: 20 de abr. 2018.

50 CAPPELLETTI, Mauro. GARTH, Bryant. Acesso à justiça. Trad. Ellen Gracie Northfleet. Porto Alegre: Fabris, 1988 , p. 9. 
O maior esforço que a ciência do direito pode oferecer para assegurar os direitos humanos é voltar-se, precipuamente, para a construção de meios necessários à sua realização nos Estados e, ainda, para o fortalecimento dos modos necessários de acesso à Justiça com vistas ao melhoramento e celeridade da prestação jurisdicional. ${ }^{51}$

É importante ressaltar que a atuação do Conselho Nacional de Justiça, especialmente após a entrada em vigor da Resolução no 125/2010, demonstra a preocupação do Poder Judiciário de afastar o convencionalismo do trâmite judicial e adotar posturas apropriadas à adoção de práticas consensuais que minimizem os problemas evidenciados por ocasião da judicialização dos conflitos.

A referida Resolução ${ }^{52}$ passou a dispor sobre a Política Judiciária Nacional de tratamento adequado dos conflitos de interesses no âmbito do Poder Judiciário, correlacionando os mecanismos de solução de conflitos à implementação de política pública direcionada a esta finalidade, estabelecendo, para tanto, regras para atuação do Conselho Nacional de Justiça "como incentivador e multiplicador junto aos Estados da União". 53

As ações adotadas pelo Conselho Nacional de Justiça foram fundamentadas na competência atribuída ao Poder Judiciário de "estabelecer política pública de tratamento adequado dos problemas jurídicos e dos conflitos de interesses"; na "necessidade de se consolidar uma política pública permanente de incentivo e aperfeiçoamento dos mecanismos consensuais de solução de litígios" e ainda na relevância e na necessidade de "organizar e uniformizar os serviços de conciliação, mediação e outros métodos consensuais de solução de conflitos", segundo a Resolução no 125/2010, do CNJ.No que se refere à definição de política pública, Bucci ${ }^{4}$ afirma que ela representa a ação governamental por intermédio de "programa que resulta de um processo ou conjunto de processos juridicamente regulados [...] visando coordenar os meios à disposição do Estado e as atividades privadas, para a realização de objetivos socialmente relevantes e politicamente determinados". Definida por Valle ${ }^{55}$ a política pública “consiste na

51 DIREITO, Carlos Alberto Menezes. A prestação jurisdicional e a efetividade dos direitos declarados. In: Revista da EMERJ, Rio de Janeiro, v. 1, n. 1, 1998, p. 142.

52 CONSELHO NACIONAL DE JUSTIÇA (CNJ). Resolução no 125/2010. Dispõe sobre a Política Judiciária Nacional de tratamento adequado dos conflitos de interesses no âmbito do Poder Judiciário e dá outras providências. Disponivel em: http://www.cnj.jus.br/images/atos_normativos/resolucao/ resolucao_125_29112010_11032016162839.pdf. Acesso em: 10 maio 2018.

53 BRAGA NETO, Adolfo. Mediação de Conflitos: Princípios e Norteadores. In: Revista da Faculdade de Direito UniRitter, Porto Alegre, n. 11, p. 29-46, 2010, p. 36.

$54 \mathrm{BUCCl}$, Maria Paula Dallari. O conceito de política pública em direito. Políticas Públicas reflexões sobre o conceito jurídico. São Paulo: Saraiva, 2006, p. 27.

55 VALLE, Vanice Regina Lírio do. Políticas públicas, direitos fundamentais e controle judicial. Belo Horizonte: Fórum, 2009, p. 36. 
decisão formulada por atores governamentais, revestida de autoridade e sujeita a sanções".

Neste contexto, há sinalização favorável à adoção de políticas públicas no Brasil como incentivo à prevenção e gestão de litígios por meio de mecanismos alternativos, o que pode ser evidenciado a partir da adoção de política pública, por parte do Poder Judiciário, com o objetivo de incentivar, aperfeiçoar, organizar e uniformizar métodos consensuais de solução de conflitos, fator que demonstra a preocupação em atender a necessidades contingentes e ainda a realização de objetivos socialmente relevantes, evidenciados pela crescente judicialização de demandas - passíveis de solução pelas próprias partes -, que muitas vezes não são resolvidas, a contento, a partir de uma decisão verticalizada.

Desse modo, é necessário que sejam encontrados novos procedimentos que visem a solucionar não apenas a demanda, mas sim o conflito e, na medida do possível, que resgate o senso de família entre os indivíduos que a compõem. ${ }^{56}$ Afinal, restaurar o bom convívio entre as pessoas é uma grande parte da resolução do embate.

É a partir do cenário apresentado que as práticas consensuais surgem como uma expectativa promissora para a busca do consenso e cooperação entre as partes (inicialmente em posições antagônicas) e a consequente antecipação da resolução dos conflitos ou mesmo a redução significativa de demandas judicializadas, o que representa a expansão do acesso à justiça, dada a maior proximidade dos indivíduos ao efetivo exercício da cidadania em razão da importância do papel que assumem neste contexto. Segundo Garapon, “Estes novos lugares descentralizados de justiça têm como objetivo não tratar do indivíduo, ou intervir directamente no social, mas favorecer uma autorreflexão crítica de todas as partes envolvidas [...] oferecendo uma instancia de discussão"57 (grifo do autor).

Desta forma, considerando que o número de ações em trâmite junto ao Poder Judiciário continua sendo preocupante faz-se necessário adotar medidas que, de forma pragmática, possam contribuir para a mudança desta conjuntura. É neste sentido que a seguir é apresentada a metodologia do Projeto de Extensão “Falando em Família" e alguns dados que demonstram sua viabilidade.

56 MERLO, Sandra Regina; MARGRAF, Alencar Frederico. Justiça restaurativa: possibilidade ou utopia? In: HELLMANN, Renê Francisco; MARGRAF, Alencar Frederico (Org.). Os efeitos do constitucionalismo contemporâneo no Direito: uma visão interdisciplinar. Telêmaco Borba: FATEB, 2014, p. 307.

57 GARAPON. Op. cit., p. 245. 


\title{
4 A contribuição do Projeto de Extensão "Falando em Família" como meio de implementação da política pública de incentivo às práticas consensuais no âmbito familiar
}

\author{
O Projeto de Extensão "Falando em Família" 58 foi lançado em 15 de maio
} de 2015, data em que se comemora o Dia Internacional da Família, fruto da parceria entre a Universidade Estadual de Ponta Grossa (UEPG), ${ }^{59}$ por meio do Departamento de Direito das Relações Sociais ${ }^{60}$ do Centro Universitário Santa Amélia (UniSecal) ${ }^{61}$ e o Tribunal de Justiça do Estado do Paraná (TJPR), por intermédio do Centro Judiciário de Solução de Conflitos e Cidadania de Ponta Grossa (CEJUSC/PG) ${ }^{62}$ e tem por objetivo a disseminação da cultura da adoção de práticas consensuais na gestão de conflitos judiciais que tramitam nas Varas de Família da Comarca de Ponta Grossa, Estado do Paraná.

0 projeto sustenta-se em três pilares: informar, ouvir e sensibilizar. A informação jurídica é socializada por meio do afastamento da complexidade na linguagem empregada a partir da utilização do lúdico para facilitar o entendimento, proporcionando um ambiente favorável para o diálogo e para a tomada de decisão por parte dos maiores interessados na solução do conflito familiar. A escuta ativa é prevalente nos encontros, o que demonstra o interesse pelas manifestações e preocupações das partes e a valorização do diálogo que também tem repercussão para os demais participantes. Por outro lado, o respeito ao silêncio é imprescindível,

58 A coordenação do projeto encontra-se sob a responsabilidade da Professora Doutora Zilda Mara Consalter, vinculada ao Departamento de Direito das Relações Sociais da Universidade Estadual de Ponta Grossa. (N. das Aa.).

59 "A Universidade Estadual de Ponta Grossa, localizada na região centro-sul do Estado, abrangendo 22 municípios em sua área de influência, foi criada pelo Governo do Estado do Paraná, através da Lei no 6.034, de 6 de novembro de 1969, e Decreto no 18.111, de 28 de janeiro de 1970, é uma das mais importantes instituições de ensino superior do Paraná, que resultou da incorporação das Faculdades Estaduais já existentes e que funcionavam isoladamente". (UEPG - A). (N. das Aa.).

60 O curso de Direito foi instalado no ano de 1958, congregando os docentes e as atividades da Faculdade Estadual de Direito de Ponta Grossa, a qual foi criada pela Lei oㅡ 2.179/1954, e reconhecida pelo Decreto Federal no 50.355/1961. A partir do ano de 1970, com a criação da Universidade Estadual de Ponta Grossa, o Departamento de Direito foi implantado, fundindo-se na nova estrutura." (UEPG - B). (N. das Aa.).

61 Com o objetivo de promover um ensino de qualidade, contribuindo para o desenvolvimento do município de Ponta Grossa, no Paraná, foi criada, em 1998, a Sociedade Educativa e Cultural Amélia Ltda., que oferta cursos de formação teórico-prática consistente, contribuindo para engrandecer os profissionais da região e promovendo a disseminação do saber na comunidade regional/nacional. Em 18 de outubro de 2018, a Secal recebeu a autorização do MEC para se tornar o Centro Universitário Santa Amélia, passando a se chamar UniSecal. (N. das Aa.).

62 De acordo com a Resolução no 125/2010, o Conselho Nacional de Justiça estabeleceu a necessidade de criação dos Centros Judiciários de Solução de Conflitos e Cidadania (Centros ou Cejuscs) pelos tribunais. Os Cejuscs são “unidades do Poder Judiciário, preferencialmente, responsáveis pela realização ou gestão das sessões e audiências de conciliação e mediação que estejam a cargo de conciliadores e mediadores, bem como pelo atendimento e orientação ao cidadão." (CNJ, 2010). (N. das Aa.). 
pois ele também é uma forma de comunicação que, apesar de não exteriorizada, pode ter reflexo positivo para aquele que adota esta postura.

O público-alvo é composto de jurisdicionados que são partes em demandas em trâmite nas Varas de Famílias da Comarca de Ponta Grossa, cujos processos são encaminhados, por determinação judicial, ao Centro Judiciário de Solução de Conflitos e Cidadania. Ao serem recepcionados pelo CEJUSC/PG, os processos passam por triagem a fim de serem avaliados os requisitos que autorizam o encaminhamento para o projeto "Falando em Família". Os requisitos estabelecidos desde o início das atividades estão direcionados à natureza da demanda, ao perfil das partes ou interessados envolvidos, bem como à residência dos litigantes. Neste sentido, os litígios devem versar sobre fixação, revisão ou exoneração de alimentos, guarda dos filhos ou divórcio, bem como questões que emergem destas demandas, como o abandono afetivo e a alienação parental. Esta delimitação objetiva abrange o maior número de demandas em que são partes ou interessados vulneráveis, compreendidos como crianças e adolescentes que, diante da fragilidade emocional e psicológica, são os mais atingidos pelo conflito. Outro fator a ser considerado é a residência das partes, uma vez que somente são convidados aqueles que, além dos requisitos anteriores, residem na cidade de Ponta Grossa, a fim de viabilizar o recebimento do convite e o deslocamento para participar da oficina.

A partir da triagem feita pelo CEJUSC/PG são expedidos convites às partes autoras das demandas para participação nas oficinas, juntamente com a intimação para a sessão de mediação, constando data, horário e local. A partir da certificação nos autos, da data da oficina, bem como da sessão de mediação, as Varas de Família ficam responsáveis pelo encaminhamento dos convites para os réus participarem das oficinas, bem como da citação para comparecerem à sessão de mediação.

As oficinas são agendadas aproximadamente duas semanas antes da data da sessão de mediação. Infere-se que o contato com o jurisdicionado mais proximamente à mencionada sessão torna o resultado consensual mais provável em razão de as informações jurídicas compartilhadas estarem mais claras e recentes na memória de cada um.

Para cada oficina são convidados aproximadamente quarenta jurisdicionados, entre autores e réus dos processos selecionados, porém há o cuidado que as partes de um mesmo processo participem de oficinas em datas diversas, com o objetivo de afastar o embate e oportunizar que cada jurisdicionado tenha acesso às informações jurídicas sem dispender tempo para discussões individualizadas e inoportunas para a finalidade da oficina. 
As oficinas ocorrem semanalmente, no período da tarde, na sede do CEJUSC/ PG e têm duração média de duas horas, sendo coordenadas por docentes, integrantes do projeto e vinculados às instituições parceiras, contando com a participação de profissional da área de Psicologia, bem como com a participação ativa de acadêmicos do Curso de Direito das instituições parceiras, os quais recebem capacitação prévia realizada pelos profissionais integrantes do projeto, bem como profissionais convidados, que compartilham suas experiências na área do Direito das Famílias e correlatas. Com esta iniciativa, os discentes têm a possibilidade de aplicar, de forma pragmática, os conteúdos teóricos obtidos em sala de aula e concomitantemente contribuir para a gestão dos conflitos de interesses na seara familiar. Atualmente, há aproximadamente cinquenta integrantes entre docentes, discentes, servidores do Poder Judiciário e profissionais das áreas da Psicologia e do Direito. Todos os colaboradores dedicam seu conhecimento e tempo voluntariamente às atividades realizadas pelo projeto.

Cada oficina é iniciada com uma breve apresentação dos integrantes e dos objetivos do projeto, bem como os motivos que levaram ao encaminhamento do convite às partes presentes. Busca-se esclarecer a importância da confidencialidade de todas as questões apresentadas e ainda que o objetivo não é o aconselhamento processual, uma vez que cada uma das partes é representada por advogado. A finalidade é ouvir aqueles que tiverem interesse em manifestarse, e ainda compartilhar informações jurídicas que possam contribuir para melhor compreender o conflito em que estiverem inseridos. Ao mesmo tempo, objetiva-se demonstrar que a troca de experiências também pode ser um fator positivo para a melhor percepção das suas condições e também da outra parte demandante que, naquele momento, pode ainda estar sendo vista como um adversário. Outra questão apresentada é a sensibilização acerca da importância do comportamento das partes envolvidas no conflito e a compreensão de que o ato de negociar os interesses, com conhecimento acerca dos seus direitos e deveres, pode ser uma forma de minimizar o embate e consequentemente reduzir os reflexos deletérios que podem ser prejudiciais à preservação dos vínculos paterno e materno-filiais.

Para facilitar a clareza, interação e comunicação entre os presentes há preocupação com a ambientalização do local para recepção dos convidados. As cadeiras são dispostas em semicírculo e faz-se uso do "objeto da palavra", que pode ser qualquer objeto com alguma representatividade para o cenário de conflitos e convergências de interesses. Como exemplo, utiliza-se o espelho com o enfoque na reflexão de que cada um de nós recebe multiplicado aquilo que oferece, ou seja, todos nós podemos observar o reflexo das condutas que adotamos, sejam elas positivas ou negativas. A ampulheta também é utilizada com a abordagem do tempo em que se ganha ao evitar o prolongamento indefinido dos extenuantes 
embates. No entanto, vários outros objetos podem ser utilizados com a finalidade de promover a reflexão sobre o contexto em que os participantes estão inseridos.

Como o "objeto da palavra" tem a finalidade de organizar a comunicação, somente aquele que com ele estiver terá condições de manifestar-se, levando em consideração que a distribuição do tempo também é um fator importante, a fim de que todos os presentes tenham oportunidade de manifestação. Com isso, cada participante tem a possibilidade de voluntariamente manifestar-se acerca dos principais aspectos que potencializam o conflito, quais informações jurídicas poderiam ser esclarecidas e ainda quais pontos poderiam ser objeto de convergência entre os envolvidos. O conteúdo abordado é direcionado pelo interesse dos presentes, mas estão relacionados a questionamentos de Direitos material e processual, bem como os reflexos da demanda judicial no âmbito familiar.

Dependendo do número de participantes faz-se opção pela melhor forma de abordagem lúdica a ser desenvolvida a fim de demonstrar que, apesar das peculiaridades de cada situação conflitiva retratada, há similaridade em circunstâncias identificadas em diferentes realidades, ou seja, apesar da singularidade do problema de cada um, este mesmo problema ocorre em diferentes cenários. Para tanto, aplicam-se dinâmicas que ressaltam a importância da empatia, da cedência e da convergência de interesses. Faz-se exibição de trechos de filmes, novelas, músicas e documentários, selecionados e inseridos durante as atividades de acordo com a percepção, por parte dos coordenadores da oficina, do perfil dos participantes, bem como a verificação das questões mais recorrentes que merecem maior reflexão. Com isso busca-se demonstrar o cuidado com a comunicação e a sensibilização das partes.

Ao final, após o agradecimento pela participação, é solicitado às partes que preencham questionário com informações relacionadas ao seu perfil, bem como sua percepção sobre o processo e as atividades desenvolvidas na oficina. Todos os documentos são devidamente arquivados e mantidos em sigilo, e os dados estatísticos extraídos, avaliados e divulgados.

Em 2015, no período de junho a dezembro, foram realizadas 22 oficinas com a participação de 63 jurisdicionados. Verificou-se que em $74 \%$ dos processos em que pelo menos uma das partes participou da oficina houve formalização de acordo e a extinção do processo, restando somente $26 \%$ sem alcançar o consenso e, por isso, prosseguiram para a instrução processual.

Em 2016, foram 27 oficinas realizadas no período de fevereiro a novembro, em que participaram 157 jurisdicionados. Nos processos em que pelos menos uma das partes participou da oficina houve $73,28 \%$ de acordos formalizados, $10,97 \%$ de processos foram extintos pela sentença judicial ou por outro 
fundamento, restando 15,75\% ainda em trâmite. Por outro lado, nos processos em que as partes, apesar de terem sido convidadas, não compareceram na oficina foram verificados $43,47 \%$ de acordos formalizados, $25,06 \%$ dos processos foram extintos na fase de instrução processual e 31,47\% encontram-se em trâmite.

A partir destes dados é possivel observar que nos processos em que houve participação nas oficinas o percentual de acordos formalizados foi maior em aproximadamente $30 \%$, reduzindo-se, desta forma, o percentual de processos em que houve extinção pela sentença judicial ou outro fundamento. Além disso, o percentual de processos em trâmite em que houve a participação de pelo menos uma das partes nas oficinas representa a metade em comparação aos processos em que a participação não ocorreu.

Diante da metodologia apresentada e dos dados preliminarmente levantados, é possível visualizar a importância da adoção de práticas consensuais nos moldes do projeto "Falando em Família", bem como um fértil caminho para a fundamentação e implementação destas atividades de forma institucionalizada, expandindo os horizontes de atuação e ampliando as possibilidades de gestão dos conflitos judicializados no âmbito familiar.

\section{Considerações finais}

É praticamente impossível falar em ausência de conflito, pois estes são inerentes à convivência humana. No entanto, é necessário o constante aprendizado para viabilizar a gestão de conflitos de forma a minimizar as suas consequências por meio da empatia, do diálogo e também do ato de cedência por parte de cada um dos envolvidos, a fim de afastar o quanto possível os eventuais danos que possam ser gerados a partir de uma decisão equivocada.

Cumpre destacar que a educação para a adoção de práticas consensuais e a informação jurídica são capazes de modificar não somente as condições pessoais da parte envolvida no conflito, mas sua situação de cidadão. Essa mudança torna-o capaz de problematizar fatos e buscar, por si só, as soluções adequadas e pertinentes para o seu conflito, sem a necessidade de recorrer ao Estado-juiz para fazê-lo.

Para que a humanização do Direito ocorra, faz-se imperioso que as partes compreendam e reconheçam efetivamente os seus direitos e obrigações e, então, se sintam aptas para tomar decisões em relação ao conflito que vivenciam. Desta forma, desmitifica-se a cultura da sentença como única saída plausível para solucionar questões que podem ser gerenciadas pelos seus principais interessados. 
Diante da metodologia empregada e dos dados apresentados como resultados parciais é possível confirmar a hipótese inicialmente aventada. Nesse sentido, a institucionalização de atividades voltadas à gestão dos conflitos jurídicofamiliares, como as ações desenvolvidas pelo Projeto "Falando em Família", contribui para capacitar os envolvidos para agirem e propiciarem a propagação à sociedade da necessidade da informação jurídica como instrumentos de exercício da cidadania e de humanização do Direito.

O Projeto "Falando em Família" dá cumprimento aos termos do Objetivo de Desenvolvimento Sustentável no 16 - Paz, Justiça e Instituições Eficazes - por possibilitar a atuação pacífica dos membros da sociedade e garantir a igualdade de acesso à justiça para todos, fundado em ações locais que discutem e colaboram com a superação de desafios globais.

A adoção de política pública direcionada à ampliação das práticas consensuais no Direito das Famílias contribui na conscientização de um número maior de pessoas quanto aos reflexos favoráveis da resolução antecipada do conflito, principalmente em relação às partes envolvidas, em especial aos filhos vulneráveis que, na maioria das vezes, são aqueles mais atingidos. A prevenção de demandas judiciais extenuantes e prolongadas também pode ser viabilizada com a disseminação de ações voltadas à justiça preventiva, em que se busca a convergência das vontades e interesses das partes envolvidas, evitando-se o quanto possível o encerramento do feito com base em uma sentença judicial verticalizada.

\title{
The importance of the adoption of the consensual practices to manage family conflicts as a public policy to realize the United Nations objective (sustainable development)
}

\begin{abstract}
Transformations in concept of family brought social and legal recognition of family new arrangements. Faced with this complexity the divergences and confrontations were intensified as well as their consequent judicialization. As a result, mechanisms that aim to reduce the procedural burden of the Judiciary, give options to decision-makers, and preserving the parental bonds are being seeked. So, the research problem consists in identify the contribution of consensual practices to manage legal-family conflicts as public policy to fulfill the objective of sustainable development. The scientific method of approach is the logical-deductive, starting from the study of transformations in family and the judicialization of their conflicts. After, it evaluates the guarantee of the right of access to justice as a human right through public policies of social pacification. Finalizing the approach, it discusses contributions of "Falando em Família" Extension Project as one of these public policies. As a partial result, methodology and the partial data demonstrates the effectiveness of that action, which respects the guidelines of the National Council of Justice and one of the Sustainable Development Objectives (established by the United Nations).
\end{abstract}

Keywords: Neoconstituted families. Consensual measures. Conflict settlement. Public policy. Sustainable development. 
Summary: 1 Introduction - $\mathbf{2}$ The family`s transformation as an indicative element of the growing of the family conflicts judicialization $\mathbf{-} \mathbf{3}$ The guarantee of the right of access to justice as an human right through public politics aimed at the social pacification $-\mathbf{4}$ The contribution of the extension project "Falando em família" as a way to the public politic of promotion of consensual practices in the familiar sphere - 5 Final considerations - References

\section{Referências}

BAUMAN, Zygmunt. Amor líquido: sobre a fragilidade dos laços humanos. Trad. Carlos Alberto Medeiros. Rio de Janeiro: Zahar, 2004.

BENETI, Sidnei Agostinho. Resolução alternativa de conflitos (ADR) e constitucionalidade. In: Revista do Instituto dos Advogados de São Paulo (IASP)., n. 9, p. 104-121, jan.-jul. 2002.

BRAGA NETO, Adolfo. Mediação de Conflitos: Princípios e Norteadores. Revista da Faculdade de Direito UniRitter, Porto Alegre, n. 11, p. 29-46, 2010.

BRASIL. Constituição da República Federativa do Brasil de 1988. Disponível em: http:// www.planalto.gov.br/ccivil_03/constituicao/constituicao.htm. Acesso em: 18 abr. 2018.

BRASIL. Decreto no 99.710, de 21 de novembro de 1990. Promulga a Convenção sobre os Direitos da Criança. Disponível em: http://www.planalto.gov.br/ccivil_03/ decreto/1990-1994/d99710.htm. Acesso em: 18 abr. 2018.

BRASIL. Lei no 4.121 de 27, de agosto de 1962. Dispõe sobre a situação jurídica da mulher casada. Disponível em: http://www.planalto.gov.br/ccivil_03/leis/1950-1969/L4121.htm. Acesso em: 18 abr. 2018.

BRASIL. Lei no 6.515, de 26 de dezembro de 1977. Regula os casos de dissolução da sociedade conjugal e do casamento, seus efeitos e respectivos processos, e dá outras providências. Disponível em: http://www.planalto.gov.br/ccivil_03/leis/L6515.htm. Acesso em: 18 abr. 2018.

BRASIL. Lei no 8.069, de 13 de julho de 1990. Dispõe sobre o Estatuto da Criança e do Adolescente e dá outras providências. Disponível em: http://www.planalto.gov.br/ccivil_03/ leis/L8069.htm. Acesso em: 18 abr. 2018.

BRASIL. Lei no 10.406, de 10 de janeiro de 2002. Institui o Código Civil. Disponível em: http://www.planalto.gov.br/ccivil_03/leis/2002/L10406.htm. Acesso em: 18 abr. 2018.

BRASIL. Lei $\mathrm{n}^{\circ} 10.741$, de $1^{\circ}$ de outubro de 2003. Dispõe sobre o Estatuto do Idoso e dá outras providências. Disponível em: http://www.planalto.gov.br/ccivil_03/leis/2003/ L10.741.htm. Acesso em: 18 abr. 2018.

BRASIL. Lei no 12.852, de 5 de agosto de 2013. Institui o Estatuto da Juventude e dispõe sobre os direitos dos jovens, os princípios e diretrizes das políticas públicas de juventude e o Sistema Nacional de Juventude - SINAJUVE. Disponivel em: http://www.planalto.gov.br/ ccivil_03/_ato2011-2014/2013/lei/I12852.htm. Acesso em: 18 abr. 2018. 
BRASIL. Lei no 13.105, de 16 de março de 2015. Institui o Código de Processo Civil. Disponível em: http://www.planalto.gov.br/ccivil_03/_ato2015-2018/2015/lei/l13105. htm. Acesso em: 20 abr. 2018.

BRASIL. Lei no 13.140, de 26 de junho de 2015. Dispõe sobre a mediação entre particulares como meio de solução de controvérsias e sobre a autocomposição de conflitos no âmbito da administração pública. Disponível em: http://www.planalto.gov.br/ccivil_03/_ato20152018/2015/lei/l13140.htm. Acesso em: 20 abr. 2018.

BUCCI, Maria Paula Dallari. O conceito de política pública em direito. Políticas Públicas reflexões sobre o conceito jurídico. São Paulo: Saraiva, 2006.

CAPPELLETTI, Mauro. GARTH, Bryant. Acesso à justiça. Trad. Ellen Gracie Northfleet. Porto Alegre: Fabris, 1988.

COMPARATO, Fábio Konder. A afirmação histórica dos direitos humanos. 5. ed. rev. e atual. São Paulo: Saraiva, 2007.

CONSELHO NACIONAL DE JUSTIÇA (CNJ). Resolução nำ 125/2010. Dispõe sobre a Política Judiciária Nacional de tratamento adequado dos conflitos de interesses no âmbito do Poder Judiciário e dá outras providências. Disponível em: http://www.cnj.jus.br/images/ atos_normativos/resolucao/resolucao_125_29112010_11032016162839.pdf. Acesso em: 10 maio 2018.

CONSELHO NACIONAL DE JUSTIÇA (CNJ). Justiça em números: publicado em 2015 referente ano-base 2014. Disponível em: http://www.cnj.jus.br/programas-e-acoes/pj-justica-emnumeros. Acesso em: 20 maio 2018.

CONSELHO NACIONAL DE JUSTIÇA (CNJ). Justiça em números: publicado em 2016 referente ano-base 2015. Disponível em: http://www.cnj.jus.br/files/conteudo/arquivo/2016/10/ b8f46be3dbbff344931a933579915488.pdf. Acesso em: 15 maio 2018.

CONSELHO NACIONAL DE JUSTIÇA (CNJ). Justiça em números: publicado em 2017 referente ano-base 2016. Disponível em: http://www.cnj.jus.br/files/conteudo/arquivo/2017/12/ b60a659e5d5cb79337945c1dd137496c.pdf. Acesso em: 15 maio 2018.

DIAS, Maria Berenice. Manual de direito das famílias. 8. ed. rev. e atual. São Paulo: Revista dos Tribunais, 2011.

DIREITO, Carlos Alberto Menezes, A prestação jurisdicional e a efetividade dos direitos declarados. In: Revista da EMERJ, Rio de Janeiro, v. 1, n. 1, 1998.

ENGELS, Friedrich. A origem da família, da propriedade privada e do Estado. 12. ed. Rio de Janeiro: Bertrand Brasil, 1991.

FUSTEL DE COULANGES, Numa Denis. A cidade antiga. 4. ed. Trad. Fernando Aguiar. São Paulo: Martins Fontes, 1998.

GAMA, Guilherme Calmon Nogueira da; ANDRIOTTI, Caroline Dias. Breves notas históricas da função social no Direito Civil In GAMA, Guilherme Calmon Nogueira da (Coord.). Função social no direito civil. 2. ed. São Paulo: Atlas, 2008.

GARAPON, Antoine. O guardador de promessas. Justiça e democracia. Trad. Francisco Aragão. Lisboa: Instituto Piaget, 1996. 
GILISSEN, John. Introdução histórica ao direito. 2. ed. Trad. A. M. Hespanha e L. M. Macaísta Maíheiros. Lisboa: Calouste Gulbenkian, 1995.

INSTITUTO BRASILEIRO DE GEOGRAFIA E ESTATÍSTICA - IBGE (2015). Estatísticas do Registro Civil 2015, v. 42. Rio de Janeiro: IBGE, 2016. Disponível em: https://biblioteca.ibge.gov.br/ visualizacao/periodicos/135/rc_2015_v42.pdf. Acesso em: 15 maio 2018.

INSTITUTO BRASILEIRO DE GEOGRAFIA E ESTATÍSTICA IBGE (2016). Disponível em: https:// www.ibge.gov.br/estatisticas-novoportal/sociais/populacao/9110-estatisticas-do-registrocivil.html?\&t=resultados. Acesso em: 15 maio 2018.

LÔBO. Paulo. Direito civil: família. 4. ed. São Paulo: Saraiva, 2011.

MANCUSO, Rodolfo de Camargo. Acesso à justiça: condicionantes legítimas e ilegítimas. 2. ed. rev., atual. e ampl. São Paulo: Revista dos Tribunais, 2015.

MERLO, Sandra Regina; MARGRAF, Alencar Frederico. Justiça restaurativa: possibilidade ou utopia? In: HELLMANN, Renê Francisco; MARGRAF, Alencar Frederico (Org.). Os efeitos do constitucionalismo contemporâneo no direito: uma visão interdisciplinar. Telêmaco Borba: FATEB, 2014.

NALINI, José Renato. A rebelião da toga. 3. ed. rev., atual. e ampl. São Paulo: Revista dos Tribunais, 2015.

ORGANIZAÇÃO DAS NAÇÕES UNIDAS NO BRASIL (ONU). Agenda 2030. Disponível em: https:// nacoesunidas.org/pos2015/ods16/. Acesso em: 25 maio 2018.

PEREIRA, Caio Mario da Silva. Instituições de direito civil. Rio de janeiro: Forense, 2011.

PEREIRA, Caio Mario da Silva. Reconhecimento de paternidade e seus efeitos. 5. ed. Rio de Janeiro: Forense, 1998.

PEREIRA, Dirce do Nascimento Pereira. O reconhecimento da paternidade simultânea e seus reflexos jurídicos na seara sucessória. In: CONSALTER, Zilda Mara; PEREIRA, Dirce do Nascimento Pereira (Org.). Questões controversas do direito das famílias na contemporaneidade. Belo Horizonte: Arraes, 2015.

PEREIRA, Rodrigo da Cunha (Org.) Tratado de direito das famílias. Belo Horizonte: IBDFAM, 2015.

ROCHA, Marco Túlio de Carvalho. O conceito de família e suas implicações jurídicas: teoria sociojurídica do direito de família. Rio de Janeiro: Elsevier, 2009.

SALM, João; LEAL, Jackson da Silva. A justiça restaurativa: multidimensionalidade humana e seu convidado de honra. In: Sequência, n. 64, p. 195-226, jul. 2012.

SANTOS, Boaventura de Sousa; CHAUÍ, Marilena. Direitos humanos, democracia e desenvolvimento. São Paulo: Cortez, 2013.

SEN, Amartya Kumar. Desenvolvimento como liberdade. Trad. Laura Teixeira Motta. São Paulo: Companhia das Letras, 2000.

TEIXEIRA, Ana Carolina Brochado. Novas entidades familiares. In: Revista Trimestral de Direito Civil. Rio de Janeiro, v. 16, , out./dez., 2003. 
TOFFLER, Alvin. A terceira onda. 32. ed. Trad. João Távora. Rio de Janeiro: Record, 2014.

UNISECAL. Sobre nós. Disponível em: http://unisecal.edu.br/sobre-nos/. Acesso em: 12 dez. 2018.

UNIVERSIDADE ESTADUAL DE PONTA GROSSA (UEPG - A). Histórico. Disponível em: http:// portal.uepg.br/institucional/universidade/historico.php. Acesso em: 10 maio 2018.

UNIVERSIDADE ESTADUAL DE PONTA GROSSA (UEPG - B). Histórico do Curso de Direito. Disponivel em: http://www.uepg.br/uepg_setores/secijur/historico.htm. Acesso em: 10 maio 2018.

VALLE, Vanice Regina Lírio do. Políticas públicas, direitos fundamentais e controle judicial. Belo Horizonte: Fórum, 2009.

WATANABE, Kazuo. Política pública do Poder Judiciário nacional para tratamento adequado dos conflitos de interesses. Revista de Processo, n. 195, maio/2011.

Informação bibliográfica deste texto, conforme a NBR 6023:2018 da Associação Brasileira de Normas Técnicas (ABNT):

PAMPLONA, Danielle Anne; PEREIRA, Dirce do Nascimento. A importância da adoção de práticas consensuais para a gestão de conflitos jurídicos-familiares como política pública de cumprimento de objetivo do desenvolvimento sustentável. Direitos Fundamentais \& Justiça, Belo Horizonte, ano 13, n. 40, p. 145-171, jan./jun. 2019.

Recebido em: 05.06.2018

Pareceres: 05.11.2018, 25.02.2019

Aceito para publicação: 26.02.2019 